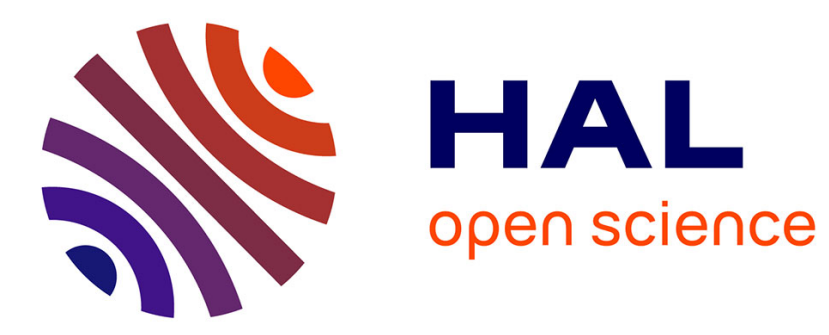

\title{
Creativity under Strong Constraints: the Hidden Influence of Design Models traduction
}

\author{
Armand Hatchuel, Milena Klasing Chen
}

\section{To cite this version:}

Armand Hatchuel, Milena Klasing Chen. Creativity under Strong Constraints: the Hidden Influence of Design Models traduction. European Review, 2017, 10.1017/S1062798716000557 . hal-01465689

HAL Id: hal-01465689

https://hal-mines-paristech.archives-ouvertes.fr/hal-01465689

Submitted on 15 Feb 2017

HAL is a multi-disciplinary open access archive for the deposit and dissemination of scientific research documents, whether they are published or not. The documents may come from teaching and research institutions in France or abroad, or from public or private research centers.
L'archive ouverte pluridisciplinaire HAL, est destinée au dépôt et à la diffusion de documents scientifiques de niveau recherche, publiés ou non, émanant des établissements d'enseignement et de recherche français ou étrangers, des laboratoires publics ou privés. 
Creativity under strong constraints: the hidden influence of design models

Armand Hatchuel* and Milena Klasing Chen**

MinesParisTech- PSL Research University, CGS, CNRS I3 UMR 9217.

60, boulevard Saint Michel, 75272 Paris Cedex 06, FRANCE.

*armand.hatchuel@mines-paristech.fr

** milena.klasing_chen@mines-paristech.fr 
In engineering design, constraints can stimulate creativity, but are also often cited as obstacles to innovation. So, do constraints hinder or foster creativity?

Despite a number of studies, the reason why constraints can have a positive or a negative impact on creativity is still unknown. In this paper, we will support theoretically and empirically that the link between creativity and constraints is not determined by the type of constraints, but by the type of "design model" used. Using C-K theory - a well-documented, general, and formalized theory of design - we first prove that the dual impact of constraints on creativity is predictable. We thenuse $\mathrm{C}-\mathrm{K}$ operators to distinguish two different design models: rule-based design and innovative design.We show that the first modelleads to a negative link between constraints and creativity; while the second model enables a positive effect. We illustrate these mechanisms through the analysis of several product developments based on both secondary and primary sources.

\section{Introduction}

In engineering design, as stated by Onarheim ${ }^{1}$, creativity and constraints are inevitably related. According to the Oxford dictionary, constraints are limitations or restrictions. When designing new products, constraints are the main reason why creativity is needed andnew solutions only emerge because of the identification of new constraints. But constraints are also often cited as the reason why creativity fails: in some cases, like in a mathematical problem, too many constraints can make it very hard to find a solution. So, do constraints hinder or foster creativity?

Despite a number of studies trying to identify why or which constraints can have a positive ora negative impact on creativity, previous literature provides no clear explanation for this dual link. Thus we are left with the need to identify the hidden variable whose influence will determine when constraints will have a positive or a negative impact on creativity.

In this paper, we will discussa new research hypothesis: the link between creativity and constraints is not determined by the type of constraints, but bythe type of design model used. We will also show both theoretical and empirical elements that supports this hypothesis.

To define what we mean by "design model" we will bear on recent developments in Design theory, namely C-K design theory ${ }^{2,3}$ that clarifies the distinction between two main design models:

i) The innovative design model,whichtriggers "expansions" and uses constraintsto enhance creativity;

ii)The rule-based design model, where constraints lead to a lock-in and to less innovations, or to no innovation at all.

In the following article we will characterize these two models using the notions and operators of C-K theory; and we will establish why they determine a positive or a negative relation between constraints and creativity.We will illustrate these mechanisms through the analysis of several product developments based on secondary sources and primary studies.

This paper is therefore composed of a literature review, showing the undetermined relation between constraints and creativity in engineering design and our research hypothesis. We then present contemporary design theory 
through the framework of $\mathrm{C}-\mathrm{K}$ theory ${ }^{2}$, and explain how it predicts the two different impacts of constraints on creativity. Afterwards, wepresent empirical material that supports these predictions: case studies in which product developments and engineering tasks face strong constraints. We conclude by stating that the innovative design model and its associated form of reasoning should be taught and used extensively to foster the positive impact of constraints on creativity.

\section{Literature review: The undetermined relation between constraints and creativity in engineering design}

In engineering design,we often refer to creativity as defined by Amabile ${ }^{4}(\mathrm{p} 126)$ : "creativity is the production of novel and useful ideasby an individual or small group of individuals working together." She specifies that this definition is product-based, and novelty and usefulness of the product are evaluated. Creative ideas are described as the building blocks of innovation ${ }^{4}$. Therefore, we will here use creativity as the cognitive process that results in innovations.

Furthermore, Amabile ${ }^{4}$ states that the highest level of individual creativity and highest innovation for organizations is reached in the intersection of resources, techniques and motivations. As stated by Rosso ${ }^{5}$, following this construct of creativity means that constraints on resources and techniques should have a negative impact on creativity, reducing the innovative outcomes of the process. He furthermore states that constraints are also often described asreducing the "intrinsic motivation", which also should have a negative effect on the outputs of the creative process.

Despite this, many papers in engineering design support the idea that constraints lead to innovations, insisting on the positive effect constraints have on creativity.Literature on frugal innovation ${ }^{6}$, on jugaad innovation ${ }^{7}$ and on resource constrained product development ${ }^{8}$ cites the lack of resources, an obvious type of constraints, as the main trigger forcreative solutions. Authors defend that having less resources available forces to disrupt existing solutions, since the lack of resources make it impossible to adopt a regular solution. In these cases the severity of the constraints,like for instance dividing costs by 10 or 100 , is often cited as what made them effective in triggering creativity. Keupp and Gassmann ${ }^{9}$ also support a positive influence of knowledge constraints in the creation of radical innovation, leading to the reuse of previously unused knowledge andto knowledge re-organization.

The link between creativity and constraints in engineering design is therefore undetermined. Onarheim ${ }^{1}$ speaks of a dual link between creativity and constraints, since constraints seem to have a positive and a negative influence according to the setting. Rosenzweig and Mazursky ${ }^{10}$ also show that constraints can both enhance and limit creativity. According to their study some constraints on knowledge can lead to improve innovativeness, but extreme knowledge constraints reduce the firm's innovativeness.

\subsection{Exploring the causes of the undetermined link}

Reasons for this dual link have been looked for in the nature of constraints. Several efforts to classifyconstraintsand prove their contingent effectshave been attempted ${ }^{11}$.The classification proposed by Lawson and Dorst ${ }^{11}{ }^{\text {is }}$ done according 
to three dimensions. The first dimension is the generator of the constraint, whocan be the designer, the client, the user or legislators. The second dimension defines a constraint as being internal to the designed product or contextual. The third dimension can beseparated into four types:functional, practical/technical, compositional or symbolic constraints. However, researchers found no evidence that the type of constraint was linked to a positive or negative influence on creativity.

Another hypothesis that has been tested without success is if being an individual or a team might be the explainingvariable for the impact of constraints on the creative process.Researchers have also investigated the influence of the designer's personality. However, Onarheim ${ }^{1}$ finds that the same designer can in one project perceive a type of constraint as enhancing his creativity, and in another project see the same type of constraint as limiting his options. Although Rosso $^{5}$ observes that team dynamics seem to influence this link, he states the link is not direct, and that the team dynamics, which he classified as "enabling" or "disabling" dynamics, can evolve over time.

We can thereforestate that the inconclusiveness of the existing literature reinforces the hypothesis that there may exist a hidden factor that affects the relationship between the outcomes of the creative process and constraints, as illustrated in Figure 1. This factor has not been identified so far;and previous studies seem to reject the idea that this hidden factor could be found in some typology of constraints. Our research has explored a different path. We will explain this dual link by the influence of a new type of variable, the type of design process that is used, which we call a design model.

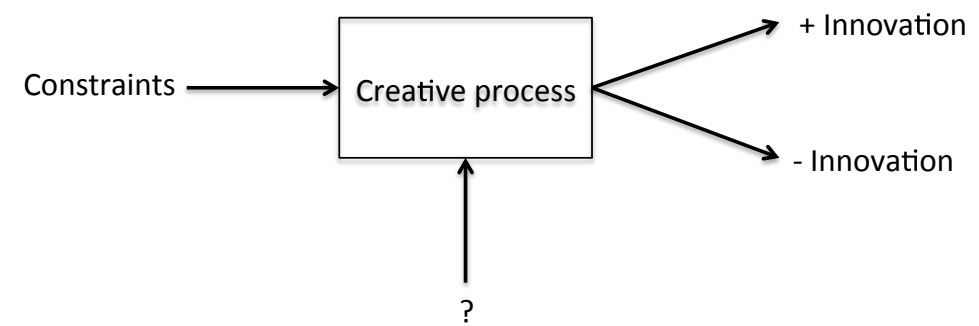

Figure 1 - Modeling the effect of constraints on creativity through the hypothesis of a hidden factor

\section{Thevariable impact ofconstraints on creativity:a prediction of design theory}

$\mathrm{C}-\mathrm{K}$ design theory ${ }^{2}$ has been recognized as a general and rigorous theory of design reasoning. We will now establish that C-K design theory:

i) Predicts the dual link between constraints and creativity;

ii) Helps to identify two design models that determine a positive or a negative link between constraints and creativity.

\subsection{Introduction to $C$ - $K$ theory}

We hereby propose a quick introduction to $\mathrm{C}-\mathrm{K}$ theory. In $\mathrm{C}-\mathrm{K}$ theory we have two different spaces, a concept (C) space and a knowledge (K) space. The $\mathrm{C}$ space contains propositions that do not have a logical status, which means that they are undecidable in $\mathrm{K}$, neither true nor false. The $\mathrm{K}$ space contains propositions 
with a logical status, which means that they are either true or false ${ }^{3}$. The C-space is organized as a series of properties linked to an original concept in a tree-like fashion, while the $\mathrm{K}$ space is composed in an archipelagic way. A typical $\mathrm{C}-\mathrm{K}$ representation is represented in Figure 2.

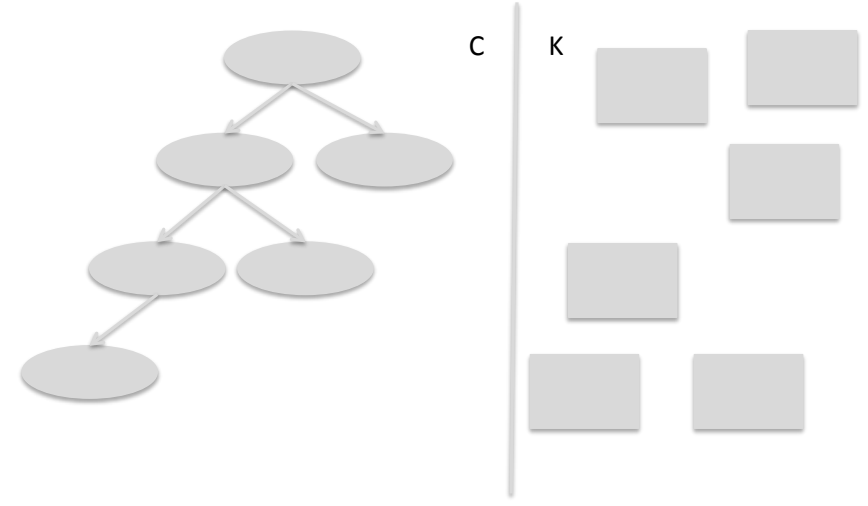

Figure 2 - Example of C-K representation

$\mathrm{C}-\mathrm{K}$ design theory explains the specific properties of design by how the $\mathrm{C}$ and K space interact and expand through four different operators:

- $\quad$ From $\mathrm{K}$ to $\mathrm{C}$ - this interaction is called a disjunction; it creates new alternatives in $\mathrm{C}$ based on the properties of the $\mathrm{K}$-space, creating a new concept.

- $\quad$ From $\mathrm{C}$ to $\mathrm{K}$ - this interaction is called a conjunction, and it means that a concept has reached a state where it achieves a logical status, and therefore becomes part of the knowledge space. This operator signals a final design has been reached.

- $\quad$ From $\mathrm{K}$ to $\mathrm{K}$ - this interaction allows creating new knowledge from the existing knowledge, through deduction, modeling, optimization or evaluation.

- From $\mathrm{C}$ to $\mathrm{C}$ - this interaction allows creating new concepts through partitioning or inclusion.

\subsection{Constraints as knowledge}

Given these basic elements of C-K theory, it is easy to establish new implications of what is called "constraints":

a) Constraints in $\mathrm{C}-\mathrm{K}$ theory are necessarily parts of the knowledge space, as they only have an impact if they are accepted as true. We will identify them as $\mathrm{K}^{*}$. Seeing constraints as knowledge extends the classic perspective of constraints as restrictions; it tells us that any restriction also describes unknown knowledge domains. For instance, if a cost is limited to a maximum $\mathrm{P}$, such proposition can also indicate that the whole set of things, services, or processes, whose cost is inferior to $\mathrm{P}$ is largely unknown to the designer. Thus the constraints also act as a potential knowledge organizer preparing new K reordering ${ }^{12}$.

b) Adding a new knowledge ( $\mathrm{K}^{*}$ in our case) in the $\mathrm{K}$ space can have different impacts both on the $\mathrm{C}$ and the $\mathrm{K}$ space, which directly predicts a complex influence.

c)In the $C$ space, new knowledge can have three different impacts: i) it can block a previous path, hence block a design candidate; ii) it can create a new 
property,opening up a new path; and iii) it can re-open a previously blocked or pending $\mathrm{C}$ path.

d) In the $\mathrm{K}$ space, adding $\mathrm{K}^{*}$ can lead to a $\mathrm{K}$-restructuring ${ }^{13}$,fostering the production of new knowledge or invalidating a given knowledge base, which will no longer be accepted astrue.

These four types of impact are illustrated in Figure 3.
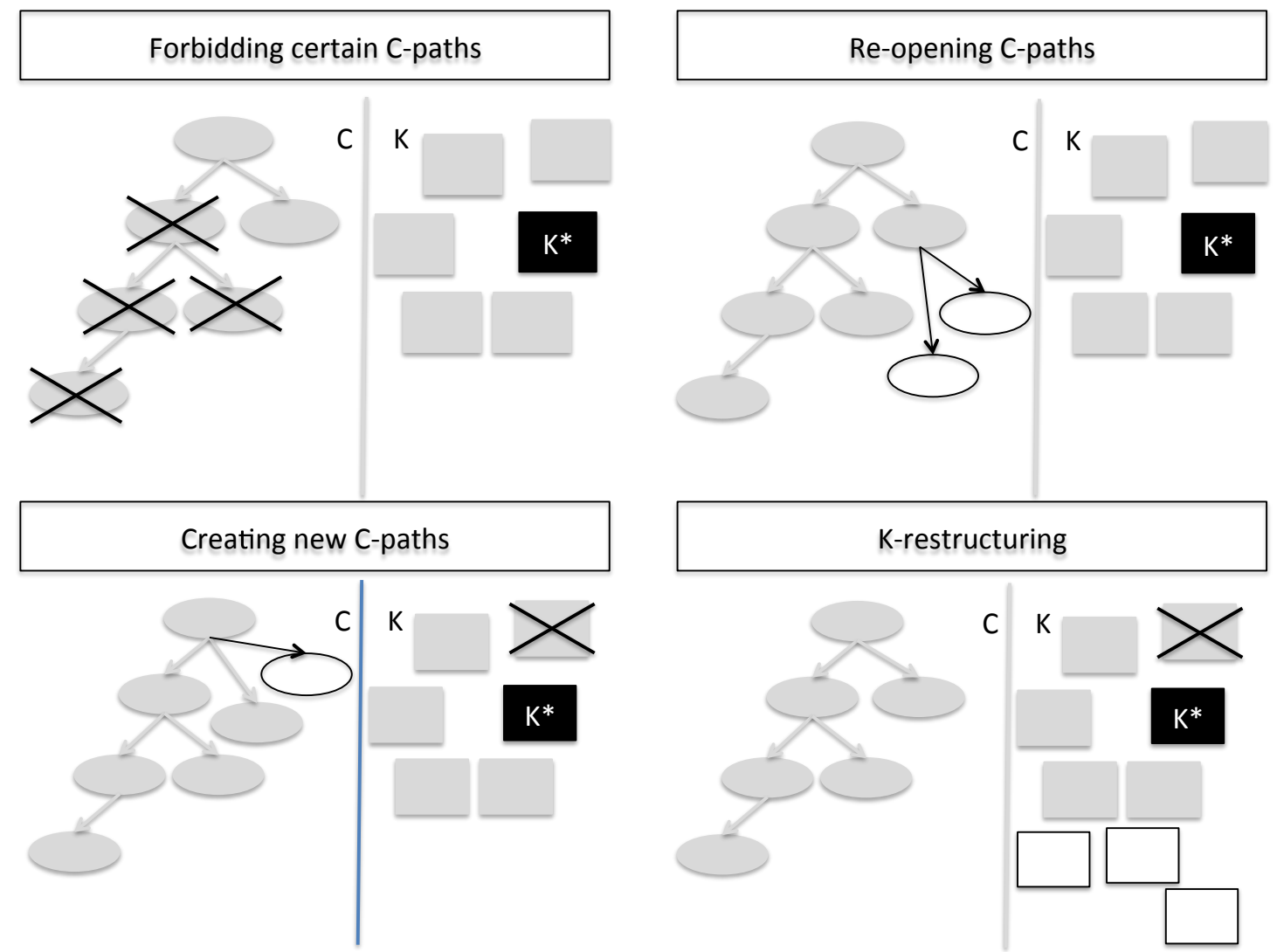

Figure 3 - Effect of adding a new knowledge in the $\mathrm{C}$ and $\mathrm{K}$ spaces

3.3 Defining design models as enablers of constraints' impacts: rule-based design and innovative design

We will now model the design reasoning when constraints are added in the C-K framework as described in two important currents inside design theories, rulebased design and innovative design. We find they have different approaches to constraints.

One example of rule-based design is systematic design, in which according to Pahl and al. ${ }^{14}$, "the main task of engineers is to apply their scientific and engineering knowledge to the solution of technical problems, and then to optimize those solutions within the requirements and constraints set by material, technological, economic, legal, environmental and human-related considerations."This definition is modeled in Figure 4. Therefore constraints are seen as considerations that reduce the possible scope of solutions, since they are the borders and limitations needed to choose an optimum solution. 

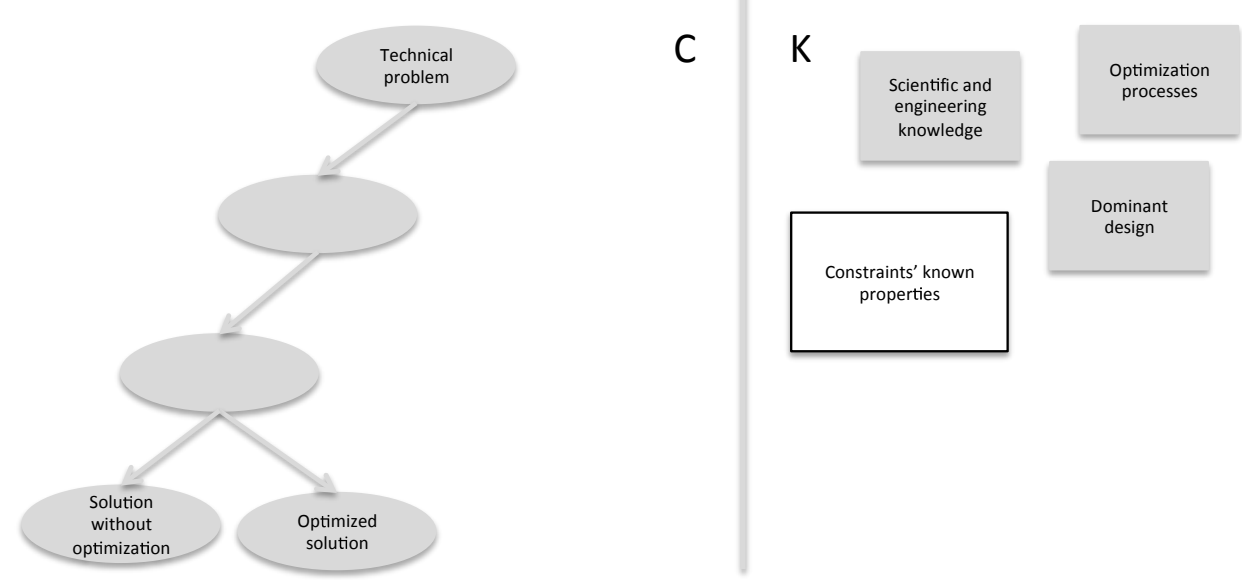

Figure 4-Modeling the approach of constraints in systematic design

In rule-based design, efforts are often focused on exploring improvements of an existing product. The identity of the product, which is defined by the set of main properties of this product, is not challenged. So when a constraint in rulebased design forbids an important property of the product, this is limiting, since alternatives would challenge the identity of the product. In $\mathrm{C}-\mathrm{K}$ theory this means only small changes in the $C$ space $(\delta C)$.

Another characteristic of rule-based design theories is that the goal is to propose solutions with a maximum reuse of existing knowledge ${ }^{15}$. This means that any constraint that would demand an important creation of new knowledge to be overcome would also be limiting, since creating a lot of new knowledge is considered too costly. This means that there are only small changes in the $\mathrm{K}$ space $(\delta \mathrm{K})$.

In innovative design theories, on the contrary, efforts are focused on challenging all the properties of the product and exploring a maximum of alternatives. As stated by Elmquist and Segrestin ${ }^{16}$, in innovative design theories the identity of the product is deliberately challenged.The introduction of a new knowledge, even if it closes down a certain C-path, also leads to challenge other aspects of the identity of the product, and therefore opens up new paths.So this approach fosters creativity, since it forces the emergence of new knowledge and concepts once a constraint exists. When modeled in the $\mathrm{C}-\mathrm{K}$ theory framework, we observe both big changes in the $\mathrm{C}$ and $\mathrm{K}$ spaces $(\Delta \mathrm{C}$ and $\Delta \mathrm{K})$.

The two models and the different impacts of constraints on creativity according to the design model can therefore be summarized as seen in table 1 .

Table 1 - Identity of the object in the two design models and impact of constraints

\begin{tabular}{lll}
\hline Design model & Rule-based design & Innovative design \\
\hline $\begin{array}{l}\text { Approach to the identity of } \\
\text { the object }\end{array}$ & $\begin{array}{l}\text { No change in the identity of } \\
\text { the object }\end{array}$ & $\begin{array}{l}\text { Deliberately challenges the } \\
\text { identity of the object }\end{array}$ \\
$\begin{array}{ll}\text { Changes in C and K spaces } \\
\text { Constraint as... }\end{array}$ & $\begin{array}{l}\text { K spaces }(\delta \mathrm{C} \text { and } \delta \mathrm{K}) \\
\text { Limiting possible choices }\end{array}$ & $\begin{array}{l}\text { Big changes in the } \mathrm{C} \text { and the } \mathrm{K} \\
\text { spaces }(\Delta \mathrm{C} \text { and } \Delta \mathrm{K})\end{array}$ \\
Effect of constraints & Reduce creativity & $\begin{array}{l}\text { new design spaces } \\
\text { Increase creativity }\end{array}$ \\
\hline
\end{tabular}

We will test the proposed explanation through the study of products developed under constraints in the next part. 


\section{Empirical case studies: how the design model enables increased creativity through constraints}

In this part we will describe two cases in which the authors participated in a resource constrained product development, to show how the design reasoning affects the relationship between constraints and creativity. We will then model different innovative products, based on secondary sources, developed under different types of strong constraints, to show that innovative design reasoning allowed fostering creativity independently of the type of constraint.

\subsection{Designing a new mobility system under resource constrains}

In our first case, the authors had the opportunity, through an intervention research ${ }^{17}$ from beginning of 2012 to the beginning of 2015, to accompany the development of mobility offers with a strong resource constraint. This work took place in a public transport operator, who was eager to propose transport offers with radically lower costs. A research program on 'low cost products' was launched inside the company, and a study of 50 different products yielded two different approaches to low cost: one following rule-based design theories and called 'low cost adaptation', the other one following innovative design theories, called 'smart low cost design'18. Low cost adaptation started from an existing product and aimed maximizing cost reduction while minimizing customer utility reduction. Since this approach starts from an existing product, very little changes in its properties were proposed. Smart low cost design in turn, starts from the functions to be fulfilled and a cost goal, and therefore all the properties of the product are still to be defined.

To allow the design of mobility offers with strong resource constrains inside the operator, an oriented creativity workshop was organized. Participants were supplied the two approaches to low cost and asked to develop products following them. We observed that both approaches were used, but that participants had difficulties proposing a coherent offer usingrule-based design, following the 'low cost adaptation' strategy. This was the case since the resource constraint was too important. To preserve the identity of the object, participants were not allowed to change much in the structuring properties, which were also the main sources of cost. So the aimed cost reduction could not easily be achieved through this path. Although several small improvements were proposed, the final offer still had to have the same identity, and this strongly limited possible solutions. We saw that constraints were reducing creativity.

Inthe case of the 'smart low cost design', constraints on resources were seen asan opportunity to rethink some of the structuring properties with the highest cost. The constraint gave the actors a reason to discuss some of these properties, which in normal cases would not be challenged. The innovative design reasoning and research for new knowledge allowed proposing alternatives, leading to several different possible propositions. Here we observedthat constraints increased creativity by opening new design spaces. 


\subsection{Designing a new cockpit under certification constraints}

In our second case study, one of the authors accompanied an intervention research $^{17}$ inside an aeronautics system assemblerin 2014, during the development of a cockpit with a strong resource constraint.

The development through a rule-based design was impossible and highlighted a previously hidden constraint that blocked most innovations on the cockpit: the cockpit had to be certified, and this imposed a very specific set of technologies and procedures to build the cockpit.Adding a constraint on resources blocked that path. An effort was therefore made to apply an innovative design reasoning, and to try to open up new paths. By using the constraints as an opportunity to discuss certification, it was possible to propose new paths, like a re-discussion of certification or the launch of non-certified objects. The use of these two design models and their results are illustrated in Figure 5, where we can observe how the innovative design model allowed increasing creativity.
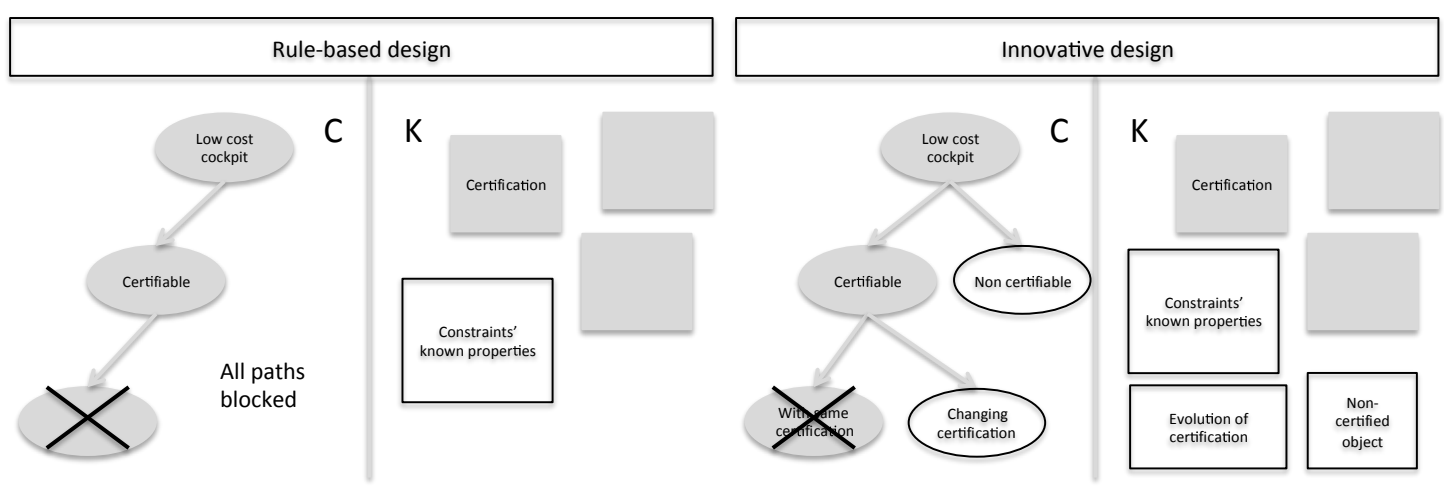

Figure 5 - Comparing a rule-based and an innovative design reasoning models applied to the low cost cockpit

\subsection{Designing a wheelchair under multiple constraints}

The nextproduct we will model, for which we sourced information from secondary sources, had several types of constraints. It was a low-cost, all-terrain, level propelled wheelchair proposed by Winter ${ }^{19}$. This was not only a resource constrained object, but also afunctionally constrained object: The wheelchair had to be adapted to rough terrain and to tight spaces, to be repairable anywhere and to provide the user a comfortable mobility during the whole day. Following a rule-based design reasoning, independent solutions for each one of the different constraints can be found. Comfortable mobility during the whole day is provided by electric wheelchairs, rough terrain wheelchairs have been developed with bigger wheels and heavier chairbody, and simpler wheelchair models can be repaired more easily.

However combining all of these constraints with a resource constraint and staying in a rule-based design model (which means not changing the main properties of a wheelchair) leads to a dead end. In this case having a great number of constraints does not leave any place for designers to work in. However, by employing an innovative design reasoning, designers searched for new knowledge both on the context for which the chair was being developed, on the usage and on the user's ergonomics, as well as on mechanics. Thisnew 
knowledge allowed proposing new properties for the wheelchair and developing an entire new C-path. The work done is modeled in a simplified C-K in Figure 6.
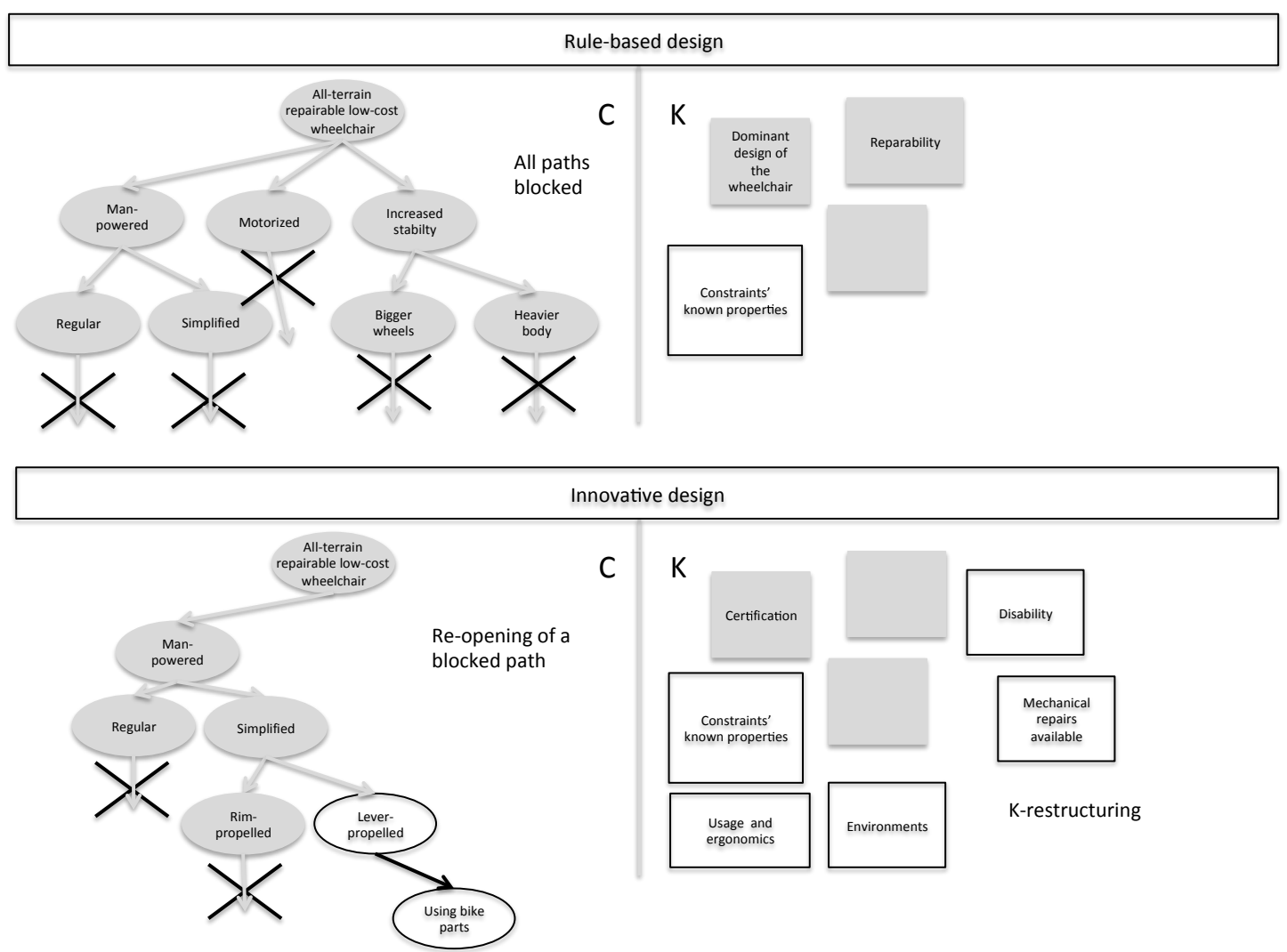

Figure 6 - Modelling the rule-based and innovative design of an all-terrain low cost wheelchair

\subsection{Designing an infant warmer under multiple constraints}

A further example of innovative product build under constraints is a recurrent example when discussing jugaad or frugal innovation: Embrace,described by Radjou et al. ${ }^{7}$ as a portable infant warmer costing less that 2 percent the cost of a classical incubator. This product, like the all-terrain wheelchair discussed previously, integrated multiple constraints. As described by Radjou et al. ${ }^{7}$, it integrated strong resource constraints; the need for portability; a constraint on the technology used, that had to work even with unreliable electrical power; and a constraint on usage, the product had to be operable without specialized training. The great number of constraints imposed here, made it impossible to propose a solution with the properties found in existing products, following rulebased design.

Through the innovative design model however, designers were able to completely rethink the product, and to propose a sleeping bag like device. It is very simple to use, having only one ok/not ok indication, so it can be operated by the infant's parents at home. This completely changed the usage and the customers of the product. And it relies on a different technology, a phase-change material, which does not need constant electrical power.

The infant warmer is a good opportunity to compare the impact of different constraints in an innovative design regime, since another resource-constrained infant warmer, the Lullaby, has been launched by GE some years ago ${ }^{20}$. An 
innovative design approach was also used, and the constraints were faced as opportunities to explore new C-paths. However, this infant warmer did not have an as strong resource constraint (it was priced 70\% cheaper than other models) and had no constraint on electrical power. Therefore the developed warmer was still adapted to hospitals only and not for home-use. Due to the fact that this warmer did not challenge all the properties of the infant warmer, it has a smaller degree of innovativeness then Embrace. It does not change the usage and the clients. Wecan therefore conclude that even following an innovative design approach, the level of innovativeness can vary. The main difference between the constraints on the two products is how far they challenge the identity of the object. In the case of Lullaby, there is no strong constraint on the technologyoron the usage. Therefore the exploration led to an innovation that is less of a breakthrough then Embrace.

The launch of a further product, Lullaby Warmer Prime(this time aimed at another segment, mostly small clinics instead of hospitals) shows that the innovativeness, in the case of constraints that do not challenge the identity of the object so strongly, depends on the cognitive resources employed and the expansion in knowledge that is searched for.

\subsection{Main empirical findings: Increasing creativity through the innovative design model}

All these cases illustrate the impact constraints on a product can have on the creative process: they show how constraints can be opportunities when using an innovative design reasoning, and how they are mostly limiting in a rule-based design. Our four cases are summarized in table 2, where we show the effects of the applied design models.

Table 2 -The four studied cases, the type of constraint and the effects of the two design models

\begin{tabular}{|c|c|c|c|}
\hline & Constraints & Rule-based design & Innovative design \\
\hline Mobility offer & Resources & Blocked & Increased creativity \\
\hline Cockpit & $\begin{array}{l}\text { Resources } \\
\text { certification }\end{array}$ & Blocked & Increased creativity \\
\hline $\begin{array}{l}\text { All-terrain } \\
\text { wheelchair }\end{array}$ & Multiple constraints & - & Increased creativity \\
\hline Infant warmer & Multiple constraints & - & Increased creativity \\
\hline
\end{tabular}

As we can observe in this table, constraints can be used to foster creativity through the innovative design model. We will now discuss these results in the CK framework.

\section{Discussion and conclusion: design models as strategies on heredity and Knowledge creation}

In this article, we used the $\mathrm{C}-\mathrm{K}$ theory to model the effect of constraints on creativity. We hypothesized that the dual link between constraints and creativity could be explained by a hidden variable: the design model.

Through our studied cases, both the empirical and those based on the literature, we can conclude that constraints will block creativity when two aspects are combined: 
i) C has a fixed structure, which means that we are not allowed to open paths in $C$ that are far away from the identity of the object, past design having an important influence;

ii) Little new knowledge $(\mathrm{K})$ is created.

This means that the impact of constraints depend of two aspects: heredity orthe importance given to past design, and the cognitive resources employed in searching for new knowledge and disjunctions from this knowledge leading to new concepts. The two design models proposed here rule-based and innovative design - differ in these two aspects, as can be seen in table 3.

Table 3 - Different approaches of heredity and new knowledge creation in the two design models

\begin{tabular}{lll}
\hline Design reasoning model & Rule-based design & Innovative design \\
\hline Heredity & Maximize & Minimize \\
New knowledge creation & Minimize & Maximize \\
\hline
\end{tabular}

In some cases however, the constraint does not challenge heredity in rulebased design, which means that alternatives can be proposed respecting the identity of the object. In these cases, as was seen in the definition given by Pahl et al. ${ }^{14}$ and modeled in Figure 4, the outcome will be a product with a lower level of innovativeness.

And in the case of innovative design, constraints that challenge the identity of the product foster creativity and lead to higher innovation levels. For a constraint that does not challenge the identity of the object, the impact of the constraint depends on the cognitive resources employed. Despite the fact that creativity is fostered by the constraints in an innovative design model, when the constraint impacts less structuring properties, there is no need to generate high levels of innovation to find a suitable answer. The degree of innovativeness therefore depends on the cognitive resources employed. If the research for new knowledge is extensive, these constraints can lead to high levels of innovation. If the research for knowledge is focused on finding a "quick-win" solution, the level of innovativeness will be lower. These results are summarized in table 4 .

Table 4 - Impact of the two design regimes according to the challenge of the constraints

\begin{tabular}{lll}
\hline Design reasoning model & Rule-based design & Innovative design \\
\hline $\begin{array}{l}\text { Constraint challenges the } \\
\text { identity of the product }\end{array}$ & Blocked & High level of innovativeness \\
$\begin{array}{l}\text { Constraint does not Low level of innovativeness } \\
\text { challenge the identity of the } \\
\text { product }\end{array}$ & $\begin{array}{l}\text { High or low level of } \\
\text { innovativeness, according to } \\
\text { the cognitive resources } \\
\text { employed }\end{array}$ \\
\hline
\end{tabular}

\subsection{Further research}

Our research allowed us to show that the design model has an influence on the link between constraints and creativity in engineering design, and we therefore contribute to a gap in literature on the explanations of the dual link between them. We furthermore found reason to believe that if constraints challenge the identity of the product or not impacts the innovativeness of the creative reasoning outcome. A limitation of our research is that it is based on only 4 cases and is not exhaustive, it would be enriching to follow the creative process in more cases and to verify the exactitude of the exposed link. 
Furthermore, in the studied cases, we mainly studied the impact of constraints on the final product on the creative process outcome. However, constraints can also exist on the design process itself, not only on the product. Hoegl et al. ${ }^{21}$ evaluated the impact of financial constraints on innovation projects, and identified five different factors that can lead to inhibit or enable innovation project performance:a bounded creativity approach, leveraging domain relevant skills, engaging objectives, team cohesion and team potency. Although we find evidence that limiting cognitive resources can have an impact on creativity in an innovative design approach, a similar study should be done on evaluating other kinds of constraints on the design process. This would add to another research gap, on the impact of constraints on the design process on creativity.

Finally, one of the managerial implications of this work is showing how different design reasoning can be introduced to overcome situations in which constraints block creativity. We only studied two cases in which the creativity block camefrom the rule-based design reasoning used, and in both cases using innovative design reasoning was the chosen solution. It would be interesting to add other cases to this, to verify our findings.

\section{References}

1. B. Onarheim (2012) Creativity from constraints in engineering design: lessons learned at Coloplast. Journal of Engineering Design, 23, 323-336.

2. A. Hatchuel and B. Weil (2003) A new approach of innovative design: an introduction to $\mathrm{C}-\mathrm{K}$ theory. International conference on engineering design, ICED.

3. A. Hatchuel and B. Weil (2009) C-K design theory: an advanced formulation. Research in Engineering Design, 19, 181-192.

4. T. M. Amabile (1988) A model of creativity and innovation in organizations. Research in organizational behavior, 10(1), 123-167.

5. B. D. Rosso (2011) Creativity and Constraint: Exploring the Role of Constraint in the Creative Processes of New Product and Technology Development Teams. PhD Thesis, University of Michigan.

6. B. C. Rao (2013). How disruptive is frugal? Technology in Society, 35, $65-73$.

7. N. Radjou, J. Prabhu and S. Ahuja (2012)Jugaad Innovation: Think Frugal, Be Flexible, Generate Breakthrough Growth(San Francisco: John Wiley \& Sons), pp. 1- 275.

8. A. SharmaandG. R. Iyer (2012) Resource-constrained product development: Implications for green marketing and green supply chains,Industrial Marketing Management ,41, 599 - 608.

9. M. M. Keupp andO. Gassmann (2013) Resource constraints as triggers of radical innovation: Longitudinal evidence from the manufacturing sector. Research Policy, 42, 1457 - 1468.

10. S. RosenzweigandD. Mazursky (2014) Constraints of Internally and Externally Derived Knowledge and the Innovativeness of 
Technological Output: The Case of the United States,Journal of Product Innovation Management, 31, 231-246.

11. B. Lawson and K. Dorst (2013) Design Expertise (New York: Taylor \& Francis), pp 1-321.

12. A. Hatchuel, B. Weil, and P. Le Masson (2013) Towards an ontology of design: lessons from $\mathrm{C}-\mathrm{K}$ design theory and Forcing, Research in Engineering Design, 24, 147-163.

13. O. Potier, J. Brun, P. Le Masson and B. Weil, (2015) How innovative design can contribute to Chemical and Process Engineering development? Opening new innovation paths by applying the $\mathrm{C}-\mathrm{K}$ method. Chemical Engineering Research and Design, first published on-line: http://dx.doi.org/10.1016/j.cherd.2015.05.040

14. G. Pahl, W. Beitz, F. Bauert and K. Grote (2007) Engineering Design: A Systematic Approach (London: Springer)

15. P. Le Masson, A. Hatchuel and B. Weil (2011) The Interplay between Creativity Issues and Design Theories: A New Perspective for Design Management Studies? Creativity and Innovation Management, 20, 217-237.

16. M. Elmquist and B. Segrestin (2009) Sustainable development through innovative design: lessons from the KCP method experimented with an automotive firm. International Journal of Automotive technology and management, 9, 229-244.

17. G. Radaelli, M. Guerci, S. Cirella and A. B. Shani (2014) Intervention Research as Management Research in Practice: Learning from a Case in the Fashion Design Industry,British Journal of Management,25, 335-351.

18. M. Klasing Chen (2013) The design and characteristics of low cost products, 1st Interdisciplinary Innovation conference, Paris, France.

19. A.G. Winter (2013) Stakeholder and constraint-driven innovation of a novel, lever-propelled, all-terrain wheelchair. Proceedings of the ASME 2013 International Design Engineering Technical Conferences \& Computers and Information in Engineering Conference IDETC/CIE 2013.

20. A. Ramdorai and C. Herstatt (2015) Study 2: Lessons from GE Healthcare: How Incumbents Can Systematically Create Disruptive Innovations. Frugal Innovation in Healthcare, Springer International Publishing, 75-103.

21. M. Hoegl, M. Gibbert and D. Mazursky (2008) Financial constraints in innovation projects: When is less more? Research Policy, 37, 1382 1391. 


\begin{abstract}
About the Authors
Armand Hatchuel is Professor, co-head of the chair of Design theory and methods for innovation at Mines ParisTech-PSL Research University. Beyond decision and optimization theory, he has developed with Benoit Weil, a new design theory (called C-K theory) that models the generative logic of new objects, and is discussed in Engineering, cognitive psychology and management journals. It had a strong impact on how creative design is organized in worldwide companies. He has published extensively and is member of journal and scientific boards. He received several awards. He is fellow of the national academy of technologies and of the Design Society.

Milena Klasing Chencurrently works in innovation in the transport sector. Her work is done in partnership with the chair on Design theory and methods for innovation at Mines ParisTech-PSL Research University. She has specialized on "low cost" and how it can lead to innovations, proposing a design model with two approaches for it.Furthermore, she has studied value creation through low cost in complex value networks.
\end{abstract}

